fifty seven (94\%) patients knew their HIV status and a 617 $(68 \%)$ were HIV positive. The TB treatment outcomes showed that $86 \%$ were successfully treated, 79 (8.6\%) not evaluated and $44(4.4 \%)$ died.

Conclusion Mine health facilities have TB Control programme performs well but an opportunity for strengthening exists.

\section{ADVERSE EFFECTS OF SMOKING; QUITTING TOBACCO}

Anasztázia Honos*. DHonos és Társa Bt, Székesfehérvár, Hungary

\subsection{6/oemed-2018-ICOHabstracts.513}

Introduction Tobacco use is the leading preventable cause of death in the world. Smoking is a real cardio-vascular risk-factor. Risk of death from coronary heart disease is much higher at smokers. One of the most important things is understanding.

I set up a 100 patients sample being more and less ,heavy smokers' from the region of Székesfehérvár and the nearby areas.

Methods I applied both the ,behavioural support' (advice, tobacco withdrawal, etc.) and pharmacotherapy (nicotine replacement therapy, bupropion, varenicline, etc.).

In both cases I followed the Prohaska's stages of changetheory: No thought of quitting; Consider quitting; Get ready to quit; Quit; Maintain tobacco-free status; Slip and try again. Results A $4 \times 3$ months period of therapy is being applied. For the time being I'm in the second quarter of my experimental help and support method.

Only a few patients succeeded to stop smoking (less than 10\%) during the first 3 months.

They are now in the „Maintain tobacco-free status' stage.

Afer the summer holidays the treatment will be continued.

Hopefully by the beginning of the Dublin-congress I can update this section of my presentation.

Conclusions Obviously I can draw the final conclusions at the beginning of the next year (March-April, 2018.). My presentation will comprise all these conclusions and the updated results, as well.

As a preliminary experience of mine: this therapy is not easy.

Understanding is not enough. Personal stories and one-toone counselling can help a lot.

\section{DATA IN THE WORKPLACE SURVEYS OF OCCUPATIONAL HEALTH SERVICES}

Sari Nissinen*, Timo Leino. Finnish Institute of Occupational Health, Helsinki, Finland

\subsection{6/oemed-2018-ICOHabstracts.514}

Introduction The purpose of workplace surveys is to investigate the hazards, exposures and strains of the work environment and evaluate their impact on employees' health and safety. In addition, occupational health service (OHS) propose actions to improve health and safety at work. The Occupational Health Act (1383/2001) sets the framework for systematic and target-oriented cooperation between OHS, employers and employees. An essential component in cooperation is the exchange of relevant data.
Methods We used the Delphi method to evaluate which data is considered relevant for information exchange in workplace surveys and how it should be documented in the information systems. Altogether thirty-seven $\mathrm{OH}$ physicians, $\mathrm{OH}$ nurses, $\mathrm{OH}$ physiotherapists and $\mathrm{OH}$ psychologists participated in the three rounds of the survey. The response rates were $76 \%$, $73 \%$ and $73 \%$, respectively. The data was analysed with the content analysis.

Result The most relevant data for information exchange between OHS and workplace in the workplace surveys were work-related health and safety risks, work load and recovery factors, recommendations for further actions and the information about the work environment, staff, professional titles and changes in the workplace.

Discussion OHS professionals use regularly information systems for documenting workplace survey data. The way the data is stored and made available in the information systems do not support enough planning and monitoring of the OHS activities and collaboration with the workplace. In order to improve the situation, better understanding of what is the relevant data for information exchange and the way the data should be structured, is needed.

\section{SHARED DECISION MAKING IN A PREVENTIVE CONSULTATION ON PREGNANCY AND WORK, AN EXPERIMENTAL VIGNETTE STUDY AMONG OCCUPATIONAL PHYSICIANS}

Carel T Hulshof*, Karen Nieuwenhuijsen, Judith K Sluiter. Academic Medical Centre, University of Amsterdam, Department Coronel Institute of Occupational Health, Amsterdam Public Health research institute, The Netherlands

\subsection{6/oemed-2018-ICOHabstracts.515}

Introduction In Occupational Health $(\mathrm{OH})$, the application of shared decision making (SDM) is not very well developed. As high level evidence on effectiveness of many $\mathrm{OH}$ interventions is scarce and often different options for $\mathrm{OH}$ interventions are available, preference-sensitive decisions in $\mathrm{OH}$ are prevalent. We studied a theoretical preference-sensitive decision in a preventive consultation by an occupational physician (OP): prevention of preterm birth in nurses exposed to physically demanding work during pregnancy. The aim was to investigate whether a more closed recommendation in one guideline ('if a work-related risk factor exists, action should be taken') versus a more open formulated recommendation ("no mandatory intervention but if distress is experienced, the worker should be advised to discuss it with her employer') in another guideline on pregnancy and work lead to differences in attitude of the $\mathrm{OP}$ to $\mathrm{SDM}$ in this case, in risk perception by the OP, and in self-efficacy to deliberate with the worker about this topic.

Methods OPs working in the health care sector were invited to participate in an online survey. We constructed vignettes about a voluntary preventive consultation by a nurse with her OP with two different recommendations on exposure to heavy physical work during pregnancy and two different case scenario's. The main issue for this consultation is if the nurse can continue her work during pregnancy in a regular way or that she should be advised to reduce or adapt her tasks. Withinsubject differences in attitudes, perception and self-efficacy, 